\title{
THE BENEFITS OF SIGN LANGUAGE FOR DEAF LEARNERS WITH LANGUAGE CHALLENGES
}

\author{
Annalene van Staden \& Gerhard Badenhorst \\ University of the Free State \\ Elaine Ridge \\ University of Stellenbosch
}

This article argues the importance of allowing deaf children to acquire sign language from an early age. It demonstrates firstly that the critical/sensitive period hypothesis for language acquisition can be applied to specific language aspects of spoken language as well as sign languages (i.e. phonology, grammatical processing and syntax). This makes early diagnosis and early intervention of crucial importance. Moreover, research findings presented in this article demonstrate the advantage that sign language offers in the early years of a deaf child's life by comparing the language development milestones of deaf learners exposed to sign language from birth to those of late-signers, orally trained deaf learners and hearing learners exposed to spoken language. The controversy over the best medium of instruction for deaf learners is briefly discussed, with emphasis placed on the possible value of bilingualbicultural programmes to facilitate the development of deaf learners' literacy skills. Finally, this paper concludes with a discussion of the implications/recommendations of sign language teaching and Deaf education in South Africa.

\section{Keywords}

Deaf learners; sign language; critical/sensitive period hypothesis; language acquisition; language developmental milestones; bilingual-bicultural programmes.

\section{INTRODUCTION}

'Substantial delays in language development are the primary hallmark of childhood deafness without early and appropriate intervention' Mayberry (2002:76).

The ability to communicate with parents, family members, friends and educators is crucial in learners' academic and social progress in life. Researchers such as Crowe (2003:199-200), Polat (2003:331-332) and Ross, Storbeck and Wemmer (2004:148) maintain that deaf learners and hearing parents, as a direct result of mutual communication problems, struggle to establish satisfactory parent-child relationship patterns. Deaf learners who are unable to communicate their needs, thoughts and experiences may experience social isolation, depression and a low self-concept. In addition, the inadequate language stimulation experienced by deaf learners, together with limited exposure to a formal language system, may result in serious communication and language acquisition deficits (Akamatsu \& 
Musselman, 1998:265-301; Goldstein \& Bebko, 2003:452; Fung, Chow \& McBride-Chang, 2005:82).

Well-documented literature studies discuss the possible role of factors such as the hearing status of parents and parental attitudes, as well as the category of hearing loss, on the language acquisition potential and psychosocial development of deaf learners (Polat, 2003). As the socialisation process begins at a very early age, with parents communicating their moral values, norms and expectations to their children, babies born deaf, who are not exposed to a natural language, e.g. sign language, have serious deficits with regard to language acquisition, academic achievement, verbal intelligence, social skills knowledge and psychological adjustment (Dyck \& Denver, 2003). Recent research findings specifically address the issues of early diagnosis and intervention (Moeller, 2000:1-9; Goldstein \& Bebko, 2003:453, Yoshinaga-Itano, 2003:26; Storbeck \& Calvert-Evers, 2008) as important prerequisites to ensure ultimate language exposure for deaf learners early in life.

In this article the authors' set out to demonstrate the merits of sign language as a communication medium and language of instruction for deaf learners, by

- critically discussing the concept of critical/sensitive periods in language acquisition;

- providing evidence of critical periods for language acquisition of deaf children;

- comparing the milestones of spoken and sign languages; and

- discussing the implications of sign language teaching in South Africa

\section{THE CRITICAL/SENSITIVE LANGUAGE ACQUISITION HYPOTHESIS}

The critical period for language acquisition is the hypothesis that language is acquired best in early childhood and is more difficult to acquire later on in life (Mayberry, 2002). A Montreal neurologist, Wilfred Penfield was one of the first scientists to propose that a superiority capacity for language acquisition in children can be linked directly to the neuroplasticity of the brain in early childhood (Penfield \& Roberts, 1959). Lenneberg's research (1967) on brain growth and clinical studies of brain damage, mental retardation and deafness further supported the notion of a critical period for language acquisition. In his view, successful language acquisition is limited to a period during a person's childhood years, the so-called 'window of opportunity' and extended between infancy and puberty (Emmorey, 2002:205). For some years empirical studies, both behavioural and neural, have provided further support for Lenneberg's hypothesis. These research results based on case studies of individual feral children (e.g. the study of Genie - $c f$. Curtiss, 1977), and/or deaf children, isolated from first language exposure until after puberty, showed a strong relationship between the age of exposure to a language and the ultimate proficiency achieved in that language (Newport, 1990; Mayberry, Lock \& Khasmi, 2002). More recent research findings, however, challenge Lenneberg's critical period hypothesis, especially his research with Down's syndrome children, discussions on brain laterality and results of feral children's language delays. Moreover, researchers argue that critical periods are not simply 'windows' that slam shut (Bruer, 1998:392). In an attempt to counter the 'rigidity of constraints implicit in the term critical period, researchers have increasingly started to use the term sensitive periods to refer to these times between infancy and puberty' when language is learned more easily (Hoskyn, 2004:97). After this sensitive period, language can be learned, but with greater difficulty and less efficiency. 
Although most researchers agree that a strong biological basis for language acquisition exists and that one must have appropriate experiences at the right developmental moments to acquire certain social, language, sensory and motor skills, the point in time when this critical/sensitive period ends is not well defined (Hoskyn, 2004:97). According to Bruer (1998:392) the 'window of opportunity' for some visual functions extends well beyond the age of 3 , until 8 or 9 years of age. Within language acquisition studies, the nature of this phenomenon has been a fiercely debated issues in psycholinguistics and cognitive science for decades. Berninger and Richards (2002:83-92) proposed that the 'window of opportunity' closes when children reach the age of 6 or 7 years, whilst other research findings suggest different sensitive periods for different language aspects. According to Neville and Bruer (2001:151) the sensitive periods for certain components of language such as phonology, grammatical processing and syntax occur during the fourth year of life and that for some language aspects such as semantics, it may continue even until puberty (i.e. 15 to 16 years of age).

According to Hoskyn (2004:97) the notion of critical/sensitive periods for language acquisition has historically provided social policymakers with the theoretical rationale for the implementation of early intervention programmes ( $c f$. Headstart programmes in the United States). Appeals for critical/sensitive periods are used to support claims about life-long impact of early experiences and the permanent damage that can be done if critical/sensitive periods are 'missed' (Bruer, 1998:392). In contrast, however, Bailey (as cited in Hoskyn, 2004:97), argues that early childhood initiatives can be justified without relying on the critical/sensitive period argument. He challenges the idea that experiences must be provided during the general age parameters of 0 to 3 years to ensure child language development proceeds normally. Moreover, some educators are sceptical about the claims that there are critical/sensitive periods for all kinds of learning. They contend that 'critical period hypothesis viewpoints' may limit skills acquisition in reading, mathematics and other school subjects (Bruer, 1998:392). In general however, most research findings have demonstrated that with increasing ages of exposure to language there is on average a lowered level of performance in many language aspects (Newport, 1990).

\section{EVIDENCE OF CRITICAL/SENSITIVE PERIODS FOR SIGN LANGUAGE ACQUISITION}

Sign language was specifically excluded from the critical/sensitive period hypothesis on the grounds that it can be successfully acquired by any person at any age (Mayberry, 2002). One of the objectives of this article is to present the evidence for applying this hypothesis to sign language. This is a complex matter since researchers are divided on whether or not there is a critical/sensitive language acquisition period for sign language. One of the reasons is that most deaf learners acquire their primary language, namely sign language, at different ages and during different cognitive development phases (Anderson \& Reilly, 2002:85) because most of them have hearing parents. This makes it difficult to compare the language acquisition milestones of deaf learners. These limited research results also directly impede the exploration of the relationship between cognitive skills and language development, another thorny issue in developmental psychology.

According to Emmorey (2002) the sensitive period hypothesis has important implications for the holistic functioning of deaf children (i.e. their language, cognition, academic, social and emotional development) because very few hearing parents of deaf learners are skilled in the 
use of sign language. In stark contrast to deaf children of hearing parents, Deaf children who have Deaf parents, are provided with natural access and exposure to sign language from birth. As a result native signing Deaf children, perform significantly better on all language aspects, compared to late signers. Mayberry and Fisher (1989) conducted two studies with deaf students $(N=71)$ who were either native signers or non-native sign language acquirers (acquired sign language between the ages of 9 and 16 years). Non-native signers appear to allocate more attention to identifying phonological shape, thus compromising their ability for retrieval and memory of lexical meaning. In contrast, native signers processed lexical structure automatically, comprehended better and made different kinds of lexical changes. These findings suggested that sign language was not as easy to learn as was originally proposed by some researchers, as well as demonstrating the superior sign language skills of native signers.

Focusing on a possible critical/sensitive period for the acquisition of sign languages, the research findings of Goldin-Meadow and her colleagues demonstrate a probable biological basis for sign language development (Bortfeld \& Whiteburst, 2001:174). In these studies profoundly deaf children with no exposure to sign language or oral language (without linguistic input from their parents) developed systems of manual sign communication that resembles many of the formal features of spoken language (Bortfeld \& Whiteburst, 2001:174). Further evidence of a possible 'critical or sensitive period' for sign language acquisition come from fMRI studies of brain activation among groups of hearing, Englishspeaking adults (born to deaf parents) who have learned ASL either before or after puberty (Hoskyn, 2004). When reading English text, extensive left hemisphere (LH) activation is found, whereas viewing American sign language (ASL) activates similar regions in the LH as well as specific areas in the right hemisphere (RH) (i.e. the superior temporal sulcus, the angular gyrus, and the posterior area of the precentral sulcus). In contrast however, no right hemisphere (angular gyrus) activation is reported for English-speaking adults who acquired ASL after puberty when they process ASL (Hoskyn, 2004:97-98).

Other researchers ( $c f$. Hart \& Risley, 1995; Bohannon, Mac Whinney \& Snow, 1990) argue that sensitive periods may be determined exogenously (i.e. by external factors) as well as by an underlying biological process (Bortfeld \& Whiteburst, 2001). Moreover, research findings have demonstrated that deaf learners with deaf parents who are exposed to sign language from birth can even attain the same linguistic milestones as hearing learners and, in some cases, even at an earlier age than hearing learners (Nicholas \& Geers, 2003; Dyck \& Denver, 2003; Anderson \& Reilly, 2002; Emorey, 2002). Since the majority of deaf learners are born into hearing families, many researchers emphasise the importance of early identification and intervention of deafness as important prerequisites to assure optimal language exposure during the more sensitive periods of language development (Moeller, 2000; Mayberry, 2002; Goldstein \& Bebko, 2003, Yoshinaga-Itano, 2003; De Nobrega, Weckx \& Juliano 2005). According to De Nobrega et al. (2005:1-10) deaf learners should be diagnosed as early as possible, preferably just after birth; and intervention should take place before the child is six months old in order to enable deaf learners to attain the same developmental milestones as hearing learners.

The research findings of Helmuth (2001), Valli and Lucas (2000), Galvan (1999) and Mayberry (1994) lend further support to a possible sensitive period for sign language acquisition. Similar to spoken languages, distinct language differences between those individuals who learn sign language as natural language (from birth) and those who learn it as 
late learners have been reported. Native signers are able to use the morphological aspects ${ }^{1}$ of sign language in more appropriate situations than late signers. According to Galvin (1999), late signers lack the appropriate inflections during conversation. In addition native signers use more spatial language and they are able to alter the grammar and syntax of their native language (Helmuth, 2001). In the Mayberry study (1994), deaf participants' tendency to make meaningful or semantic errors, as compared to phonological errors was directly related to the age at which they first learn American sign language (i.e. as age of acquisition increased there was a concomitant increase in errors that are related to the surface, phonological form of the stimulus). Moreover, as discussed in this paper, the importance of offering deaf learners adequate language exposure at an early age is advantageous to deaf learners' language development, as well as their overall psychosocial well-being. To illustrate this notion further we will compare the language acquisition milestones of deaf learners who use spoken language with those who communicate through sign language in the next section.

\section{The language acquisition milestones of deaf learners: spoken versus sign language}

\section{Spoken language}

Hearing babies learn the language of the society in which they are born through exposure to and contact with spoken language. During the sensitive period of listening and language preparedness, they develop the ability to distinguish between sounds and words, and begin to assign meanings to words. At six to eight months, hearing babies begin to understand simple language, and at around one year of age they start uttering simple words. At about five years of age they begin to understand the syntax of spoken language. The deaf baby growing up with hearing parents experiences the development of spoken language in a totally different way (Ross et al., 2004:152).

Pre-linguistic deaf learners who grow up in a linguistic world of spoken language are confronted with the extremely difficult challenge of understanding that the mysterious lip movements of other people actually represent a language. Furthermore, they are expected to assign meaning to this spoken language and to learn to speak it. In contrast to their hearing peers, the acquisition of spoken language offers few language outcomes for deaf learners. Ross et al. (2004:153) refer to Sainsbury and Loyd-Evans (1986), whose research results show that hearing three-year-old participants have an average spoken language vocabulary of between 1000 and 2000 words, whilst five-year-old deaf participants in their study acquired a spoken language vocabulary of fewer than 29 words. Moreover, research results indicate that deaf learners find the acquisition of spoken language very difficult and that their receptive as well as the expressive language skills are directly impaired by the acquisition of spoken language (Mayberry, 2002:76). During an intensive spoken language intervention programme over a period of 15 months, a deaf child of 30 months was able to learn only one word per month. In contrast with this, most hearing learners (age: 30 to 48 months) can spontaneously learn 60 to 120 words per month (Lach, Ling, Ling \& Ingram, as cited in Mayberry, 2002:76). In the Bishop investigation (1983) the understanding of spoken vocabulary among deaf participants (age: 8 to 12 years) was poorer than could be expected of a four-year-old hearing child, whilst the comprehension skills of deaf Canadian eight-year-old learners were similar to hearing four-year-olds (MacKay-Soroka, Threhub \& Thorpe, as cited in Mayberry, 2002:76).

\footnotetext{
${ }^{1}$ Morphological signs are those that are the smallest meaningful units of language. It is the formation of words from other meaningful units (Valli, 2000). 
The literature reveals that most individuals with hearing loss (more than $70 \mathrm{~dB}$ ) do not master functional speech. According to Musselman (2000:10), only about 25\% of deaf individuals primarily make use of spoken language - and specifically in situations that require the conveying of simple messages, in the presence of 'rich' contextual clues. However, numerous problems are experienced regarding concepts such as rhyme, respiration, phonation, resonance and particularly articulation. Hugo (1987), as cited in Ross et al. (2004:153) postulates that the speech of fewer than $20 \%$ of deaf individuals is readily recognisable or sounds intelligible to the average listener.

From the preceding discussion it is evident that the acquisition of spoken language is an extremely complex and difficult task for many deaf learners. Furthermore, it seems that the acquisition of spoken language cannot ensure adequate communication opportunities for deaf individuals, and also makes a limited contribution to the realisation of their language acquisition potential. This raises the question of whether it would be better for deaf learners to be exposed to sign language as a natural/first language during the sensitive language acquisition period.

\section{Sign language}

Research results provide compelling arguments that the acquisition of sign language could be of immeasurable value to deaf learners (Meier \& Newport, 1990; Petitto \& Marentette, 1991; Anderson \& Reilly, 2002:85; Emmorey, 2002; Mayberry, 2002). Researchers such as Mayberry (2002:81) contend that most deaf learners possess the potential to master sign language acquired in the visual modality as natural language. According to Mayberry (2002), Emmorey (2002) and Petitto and Marentette (1991), deaf learners who are exposed to sign language by their deaf parents from birth also start babbling (with their hands) before producing their first signs. Moreover, identical language acquisition stages for sign language and spoken language are identified namely, the syllabic babbling stage, first-word stage and a two-word stage. The sign babbling phase, just like the spoken babbling phase, is characterised by a syllabic structure that is often duplicated (for instance, 'bababa' for spoken language and cyclical movements for sign language). Petitto and Marentette (1991:1495), Emmorey (2002:170-171) and Gordon (2004:146) regard the sign babbling phase of deaf learners as an important prerequisite phase (serves as a 'bridge') for the development of sign language in a deaf baby. During this phase, deaf babies begin to link their sign articulations to visual sign patterns - thus, the sign babbling phase gradually changes over into a one- 'word' (sign) stage, then a two-'word' (sign) stage, and ultimately the acquisition of the complex morphological system of sign language by deaf learners. Furthermore, Petitto and Marentette (1991:1494) maintain that there is a 'continuity between the phonetic and syllabic forms used in deaf infants' manual babbling and their first signs' and reported that the most frequent locations and hand shapes observed in babbling were also the most frequent in deaf babies' first signs.

It seems that most researchers take the view that deaf learners acquire sign language in the same way as hearing learners acquire spoken language (Meier \& Newport, 1990; Emmorey, 2002; Mayberry, 2002). However, it seems that there are differences of opinion on the age categories of the language acquisition milestones of deaf learners. Some researchers contend that deaf babies acquire their first signs earlier than hearing learners acquire their first words (Meier \& Newport, 1990; Folven \& Bonvillian, 1991). Petitto (1994) takes a different view; he opines that these researchers erroneously interpreted the sign babbling phase of deaf babies as 'first signs'. Another aspect that cannot be disregarded is that hearing babies also communicate through signs during the syllabic babbling stage. In fact, Petitto (1994) reports 
surprising similarities that can be observed in deaf and hearing babies' use of signs during the pre-linguistic (nine to 12 months) and post-linguistic (12 to 48 months) stages of language acquisition. In contrast however, more recent findings of Anderson and Reilly (2002) confirm the work of earlier researchers such as Folvin and Bonvillian (1991), and Meier and Newport (1990). Compared to the research findings of Kirshner (2000:302) which indicated that the majority of hearing babies with normal language development only begin to utter their first words by about 13 months, deaf babies in the Anderson and Reilly (2002) investigation produced their first signs much earlier (at eight months of age). Furthermore, Anderson and Reilly (2002:84) questioned the research results reported by Petitto (1994) on the grounds that the validity and reliability of these results are limited by the study's small sample size. The Anderson and Reilly study was an extensive longitudinal study, involving 110 deaf learners (with deaf parents), originating from 16 different states in the USA. Their research findings demonstrated that that when deaf learners acquire sign language in a natural environment, it is acquired in the same way as hearing learners acquire spoken language ( $c f$. Tables 1 and 2). Anderson \& Reilly's (2002) research not only focused on the number of words (signs) of deaf learners at certain ages, but also on the content of these words. From Table 1, it is evident that at about 18 to 23 months the productive vocabulary (signs or words) of deaf learners and hearing learners compares very favourably and is more or less the same (Meier \& Newport, 1990:1-23; Anderson \& Reilly, 2002:89). Close inspection of Table 2, reveals very strong similarities between the early lexical contents of hearing and deaf learners. The use of nouns, particularly names of people, animals and food, features strongly. Another interesting observation is that hearing learners name animal sounds, whilst animal sounds are not part of deaf learners' developing vocabulary.

In addition, research findings from a South African study conducted among deaf foundation phase learners $(N=60)$ in a rural area in the Free State province, have shown that the reading and spelling abilities of deaf learners can improve significantly by exposing these learners to a visual literacy programme via SASL (Van Staden, Badenhorst \& Esterhuyse, 2008). Although this study did not compare the language milestones of orally and sign language educated deaf learners, these research results have reinforced the positive implication of early literacy intervention for deaf learners during the so-called sensitive period for language acquisition and the possible value of SASL to facilitate the development of deaf learners' English literacy skills (Van Staden et al., 2008:57-61). Furthermore, other research findings also indicated that sign language skills correlate significantly with English literacy skills ( $c f$. Strong \& Prinz, 1997, 2002; Prinz \& Strong, 1998; Hoffmeister, de Villiers, Engen \& Topol, 1998; Padden \& Ramsey, 1998; Fish, Hoffmeister \& Trasher, 2005; Niederberger \& Prinz, 2005;). All of these studies lend support to the possible applicability of Cummins' 'linguistic interdependence hypothesis ${ }^{2}$ between sign language proficiency and English literacy development.

Table 1: Descriptive statistics of deaf learners' productive sign language vocabulary

\begin{tabular}{|l|l|l|l|}
\hline Age in months & $\begin{array}{l}\text { Average number } \\
(\mathbf{n}) \text { of signs }\end{array}$ & $\begin{array}{l}\text { Median number (n) of } \\
\text { signs }\end{array}$ & Scope (n) \\
\hline $8-11$ months $(n=7)$ & 8 & 3 & $2-17$ \\
\hline $12-17$ months $(n=12)$ & 61 & 62 & $7-107$ \\
\hline
\end{tabular}

\footnotetext{
2 Cummins' linguistic interdependence theory' states that all languages share a common underlying proficiency and that cognitive and academic skills acquired in a first language will transfer to related skills in a second language (Strong \& Prinz, 2000:132).
} 


\begin{tabular}{|l|l|l|l|}
\hline $18-23$ months $(n=15)$ & 149 & 138 & $39-348$ \\
\hline $24-29$ months $(n=16)$ & 252 & 261 & $102-417$ \\
\hline $30-35$ months $(n=19)$ & 380 & 411 & $249-518$ \\
\hline
\end{tabular}

Table 2: The first 35 words (English) and signs of hearing and deaf learners respectively (Fenson et al., 1994 cited in Anderson \& Reilly, 2002:94).

\begin{tabular}{|l|l|}
\hline English words (Hearing learners) & Signs (Deaf learners) \\
\hline Daddy & Daddy \\
\hline Mommy & Mommy \\
\hline Bye & Bye \\
\hline Ball & Ball \\
\hline Baby & Baby \\
\hline No & No \\
\hline Shoe & Shoe \\
\hline Bottle & Milk \\
\hline Cookie & Cookie \\
\hline Kitty & Cat \\
\hline Dog & Dog \\
\hline Uh oh & More \\
\hline Eye & Eat/food \\
\hline Nose & Drink \\
\hline Bird & Bird \\
\hline Cracker & Cracker \\
\hline Banana & Banana \\
\hline Juice & Diaper \\
\hline Hi & Grandma \\
\hline Baabaa & Rabbit \\
\hline Moo & Clap \\
\hline Ouch & Finish (all-done) \\
\hline Woof & Cow \\
\hline Yumyum & Hat \\
\hline Balloon & Horse \\
\hline Book & Book \\
\hline Bath & Name signs (including the child's own name) \\
\hline Duck & Duck \\
\hline Peekaboo & Cry \\
\hline Nite-nite & Bath/wash \\
\hline Car & Fish \\
\hline Cheese & Tree \\
\hline Vroom & Kiss \\
\hline Keys & Sleep \\
\hline Apple & Rain \\
\hline & \\
\hline & \\
\hline
\end{tabular}




\section{THE RATIONALE FOR CHOOSING SIGN LANGUAGE AS COMMUNICATION MEDIUM AND LANGUAGE OF INSTRUCTION FOR DEAF LEARNERS}

There can be no argument about the importance of language acquisition in the overall functioning of deaf learners. That is self evident. However, which language should be considered the first/natural language of deaf learners in the school context continues to be debated (Power, 1998:371). Decisions made on the communication medium and the language of instruction directly affect deaf learners' ability to acquire language and influence the selection of strategies used to teach these learners. The three methods of instruction that have obtained most support are the aural-oral method (oralism), total communication and sign language (Killian, 2001:63). The aural-oral approach claims to build their literacy skills through the 'phonological route' (i.e. pathway to literacy based on the analysis of sounds). This approach includes auditory training, speech and lip-reading and prohibits signing or gesturing of any sort. In oralism the primary goal is the 'normalisation' of deaf learners to adapt better into a hearing world by making them more oral (Storbeck, 2005:353). In reaction to the aural-oral approach, there was a move towards the total communication approach in the 1970s. As a philosophy, this approach encourages educators to communicate with their deaf learners using simultaneous communication methods (speech, signed English, fingerspelling, gestures and speech reading) - this is referred to as Signed Supported English (Ross et al., 2004:170). Because of its emphasis on the oral expression of a language, many deaf learners experience difficulties with the total communication approach because the lexicon and grammatical structure of the two languages (sign and spoken English) is different. It seems that deaf learners cannot successfully process signs, speech and lip-reading simultaneously (Storbeck, 2005:355). Motivated by deaf orally trained learners' limited academic successes, as well as psycho-socio and culturally related challenges, the Deaf Federation of South Africa (DEAFSA) started with advocacy campaigns to introduce a bilingual-bicultural approach at Schools for the Deaf in South Africa (from the 1990's). The need for the deaf child to learn to cope with and function in both the hearing and deaf cultures has made bilingual-bicultural programmes $^{3}$ especially desirable (Reagan, 1985:276). Bilingualism in the South African context implies that South African Sign language (SASL) is introduced as a first language as early as possible, and that the verbal language of the environment (such as English) is acquired as second language, primarily in its written form (Van der Merwe \& Alant, 2000:74).

\section{IMPLICATIONS FOR SIGN LANGUAGE TEACHING IN SOUTH AFRICA}

South Africa's position on educational provision for learners with barriers to learning and development (including deaf learners) is clearly stated in the ethos of the Education White Paper 6 on Special Needs (Department of Education, 2001:7):

In accepting the inclusive approach we acknowledge that learners who are most vulnerable to barriers to learning and exclusion in South Africa are those who have been termed learners with special educational needs ...increased vulnerability has arisen largely because of the historical nature and extent of educational support provided.

\footnotetext{
3 The theoretical underpinning of bilingual-bicultural programmes for deaf learners is based on Cummins' 'linguistic interdependence theory' (Strong \& Prinz, 2000:132).
} 
Although providing an optimal educational environment in which deaf learners can thrive is an ongoing concern for policy-makers and educational practitioners alike, it remains a thorny issue. Some researchers/educationists embrace the 'philosophy of inclusion'. They argue that inclusive education is more effective than segregated education because it eliminates the stigma and questionable morality associated with special schools (De Andrade \& Ross, 1999:327). Despite growing support for mainstreaming (internationally) in special education in general (based on ethical, educational and economic related factors), however, many educationists argue that there

is ample evidence of the failure of mainstreamed programmes for deaf children .... such failure would only be exacerbated by the seriously inadequate infrastructure which exists for the deaf child, including a shortage of trained teachers and therapists, inaccessible facilities ... other problems. (Penn \& Reagan, 1995:95)

Given South Africa's history of educational language policies (based on the ideology of apartheid), issues related to the individual's human rights with regard to education, language and culture have been of considerable concern to the South African government in the postapartheid-era. It is beyond the scope of this article to discuss South Africa's language policies in detail, but the authors would like to mention that a great deal of significant work has been done at policy level to both protect and promote the 11 official languages (including SASL). Although SASL is not among the official languages, it is directly mentioned in the Constitution of South Africa (1996) and various other related policy documents ( $c f$. South African Schools Act, 1986; Language in Education Policy, 1997) (Reagan, Penn \& Ogilvy, 2006:196-197). Recently (in 2001) a National Language Board was established with the task of 'initiating and implementing strategic projects aimed at creating awareness, identifying needs and promoting SASL ... and funding projects aimed at developing SASL' (Reagan et al., 2006:198). In addition, the South African Qualifications Authority established the Standards Generating Body (SGB) for SASL and SASL interpreting with the goal of developing unit standards for SASL from NQF (National Qualifications Framework) Level 1 (Grade 7) to Level 6 (4-year degree) ( $c f$. South African Qualifications Authority, 2001, as cited in Reagan et al., 2006:199). Other initiatives include the establishment of the South African Sign language Research Programme (SASLRP), with the primary function of developing a dictionary which could facilitate communication between parents and educators of deaf learners and deaf individuals. This project was run collaboratively by a group of deaf and hearing researchers, under the auspices of the South African National Council for the Deaf ( $c f$. Penn \& Reagan, 1990; Reagan et al., 2006:193). It is however important to note that this project was criticised by some members of the Deaf community, as well as some researchers involved in Deaf Education in South Africa ( $c f$. Aarons \& Akach, 1998; Branson \& Miller, 2002; Aarons \& Reynolds, 2003). According to them the dictionary project overemphasised group-based lexical differences, whilst others were of the opinion that the emphasis on a single SASL system would denigrate the languages of deaf people (Reagan et al., 2006:193).

Despite the progress that has been made in promoting and establishing SASL as first/natural language for deaf people, in practice, many deaf learners are still not educated through the medium of SASL, because many teachers at Schools for the Deaf cannot sign and still believe that Deaf children must learn the spoken language of the area. Aarons and Akach, (1999:17) argue that 'it is in this sense that deaf learners are disabled: by the teachers and by the system that does not recognise the language which is their basic human right (i.e. SASL), and without which they literally have no access to learning'. In addition, educators teaching at Schools for 
the Deaf are still not required to have formal training and/or qualifications in Deaf Education. As a result most hearing teachers at these schools have little or no knowledge of the pedagogical implications of teaching literacy (either through oralism or sign language instruction). Thus, Storbeck (2005) strongly challenged deaf learners' placement in Special Schools. In a paper delivered at the International Special Education Conference in Glasgow, Scotland in August 2005, she spoke about the 'irony of Deaf Education' in South Africa, highlighting the fact that many deaf learners, despite their placement in Schools for the Deaf, are still excluded from equal opportunities and equal education. This 'irony' has far-reaching implications for deaf learners' academic achievement because the academic and literacy outcomes of deaf learners are substantially lower than those of hearing learners: the majority of them function below Grade 4 level when they leave school ( $c f$. Storbeck, 2005; Ross et al., 2004; Van Staden et al., 2008).

Finally, in order to create a barrier-free and supportive educational environment for deaf learners there are numerous implications that one has to consider. (UNESCO Consultation Report, 1999; Ross et al., 2004; Storbeck, 2005). Like other researchers, we contend that there should be a meaningful choice for deaf people, because 'choice of language' is fundamentally a basic human rights issue (Reagan et al., 2006:201). Hence, deaf people (i.e deaf students, deaf adults, deaf parents, including members of the Deaf Community), must be directly involved in decisions that affect them or their children; for example policy- making decisions, as well as issues related to educational placement, the language of instruction and curriculum development (Powers, 2002:238).

\section{CONCLUSION/RECOMMENDATIONS}

The literature study conducted for this research reveals the importance of early diagnosis and intervention for two important reasons. First, significant research results indicate that the sensitive period of language acquisition can also be made applicable to the acquisition of sign language. Second, Deaf learners with Deaf parents who are exposed to sign language from birth, have the ability to attain the same linguistic milestones as hearing learners and, in some cases, even at an earlier age than hearing learners. In contrast with this, 'late' language acquisition deleteriously affects the language skills of deaf learners, as well as their socioemotional development. Aspects affected directly by this include their grammatical, language processing and cognition skills.

The acquisition of spoken language seems to offer very limited communication opportunities for deaf learners. The detailed comparison of the language acquisition milestones of deaf learners who are taught by means of sign language and those taught by means of spoken language shows the immeasurable value of sign language for deaf learners. For this reason, as well as a possible loss of identity, inclusive education of deaf learners in South Africa is a contested area. According to Freire (2009:131) the educational system as a whole has to find solutions adapted to the characteristics of deaf learners 'that will help them to develop not only linguistically but also emotionally, socially and academically'. In conclusion, we would like to make the following recommendations/comments:

- Early detection of hearing loss (identification), early entry into an educational system and early contact with fluent signers are crucial elements in ensuring that deaf learners have access to and learn a language (Goldin-Meadow \& Mayberry, 2001); 
- Prompt initiation of early intervention services, including family support to hearing parents and parental training sessions to enhance their sign language skills, could prevent or greatly reduce the communication, social-emotional and developmental barriers posed by hearing loss (Moeller, 2000; Yoshinaga-Itano, 2004; Marschark, 2007; Storbeck \& Calvert-Evers, 2008). There is, however, an alternative. The Centre for Deaf Studies at the University of the Witwatersrand, in South Africa, launched an early intervention programme called HI HOPES (Home Intervention - Hearing and Language Opportunities Parent Education Services in August 2006. Through this programme parent advisors (in an unbiased way) assist parents to make decisions with regard to their child's language development, communication approach and other issues related to literacy, behaviour, play and general developmental issues and also assist with the implementation of parents' chosen approach within the authentic home environment (Storbeck \& Calvert-Evers, 2008);

- It is imperative that all educators teaching at Schools for the Deaf in South Africa be appropriately trained, have adequate knowledge about Deaf pedagogy and should be bilingual in SASL and spoken (written) language (e.g. English) (Storbeck, 2005); Moreover, a conscious effort should be made to encourage deaf students to become educators so that more deaf educators can be employed at schools for the Deaf;

- Recognising that most teachers currently cannot sign, the emphasis during the 'interim phase', should be on pre-service and continuous in-service training and the employment of deaf adults (as role models and teacher assistants) in classes in Schools for the Deaf (UNESCO Consultation Report, 1999);

- In embracing the broader notion and philosophy of Inclusive education, the possibility of transforming Schools for the Deaf into sign language medium schools ( $c f$. UNESCO Consultation Report, 1999) has to be investigated. In practice, this implies that all learners with communication barriers (i.e. deaf learners, autistic learners, learners with aphasia, etc.) who are unable to communicate with spoken speech (whether the cause is congenital or acquired) in future might have the choice to enrol at sign language medium schools where they can be instructed through SASL;

- Aarons and Akach (1999) also highlight the possibility of giving SASL a 'full status' as one of the official languages in South Africa. They argue for SASL to be offered as a school subject from Grade R to Grade 12.

- Focusing on the future of Deaf Education in South Africa, a priority goal of the South African government (National Education Department) in collaboration with tertiary institutions, should be to put tertiary education programmes in place in which education students (deaf and hearing students) can obtain specialised teaching qualifications in Deaf Education, including the opportunity to qualify themselves as professional sign language interpreters (Lotriet, 2002).

\section{REFERENCES}

AARONS, D \& P AKACH. 1998. South African Sign Language - One language or many? A sociolinguistic question. Stellenbosch papers in Linguistics, 31:1-28.

AARONS, D \& P AKACH. 1999. Inclusion and the Deaf Child in South African EducationDiscussion document.

AARONS, D \& L REYNOLDS. 2003. South African Sign Language: Changing policies and practice. In Monaghan, L, C Schmaling, K Nakamura \& G Turner (Eds), Many ways to 
be deaf: International variation in deaf communities. Washington, DC: Gallaudet University Press.

AKAMATSU, CT \& C MUSSELMAN. 1998. Development and use of a conversational proficiency interview with deaf adolescents. In Marschark, M \& MD Clark (Eds), Psychological perspectives on deafness. New York: Lawrence Erlbaum Associates Inc. 265-301.

ANDERSON, D \& J REILLY. 2002. The MacArthur Communicative Development Inventory: Normative Data for American Sign Language. Journal of Deaf Studies and Deaf Education, 7(2): 83-106.

BERNINGER, VW \& TL RICHARDS. 2002. Brain literacy for educators and psychologists. Boston: Academic Press.

BOHANNON, JN, B MAC WHINNEY \& C SNOW. 1990. No negative evidence revisited beyond learnability or who has to prove what to whom. Developmental Psychology, 26:221-226.

BORTFELD, H \& GJ WHITEBURST. 2001. Sensitive periods in first language acquisition. In Bailey, DB, J Symons \& JW Lichtman (Eds), Critical thinking about critical periods. Baltimore, Maryland: Paul Brookes Publishing Company. 173-192

BRANSON, J \& D MILLER. 2002. Dammed for their difference. The cultural construction of deaf people as disabled. Washington, DC: Gallaudet University Press.

BRUER, JT. 1998. The brain and child development: Time for some critical thinking. Public Health Reports, 113:388-397.

CROWE, TV. 2003. Self-esteem scores among deaf college students: An examination of gender and parents' hearing status and signing ability. Journal of Deaf Studies and Deaf Education, 8(2):199-206.

CURTISS, S. 1977. Genie: A psycholinguistic study of a modern-day 'wild-child.' New York: Academic Press.

DE ANDRADE, V \& E ROSS. 1999. Attitudes of a group of deaf adolescents towards educational inclusion. South African Journal of Education, 19(4):327-340.

DE NOBREGA, M, LL WECKX \& Y JULIANO. 2005. Study of hearing loss in children and adolescents, comparing periods of 1990 - 1994 and 1994 - 2000. International Journal of Paediatric Otorhinolaryngology, 1-10.

DEPARTMENT OF EDUCATION, 2001. Education White Paper 6: Special Needs Education.

DYCK, MJ \& E DENVER. 2003. Can the emotion recognition ability of deaf children be enhanced? A pilot study. Journal of Deaf Studies and Deaf Education, 8(3):348-356.

EMMOREY, K. 2002. Language, cognition and the brain: Insights from sign language research. New York: Lawrence Erlbaum Associates Inc.

FISH, S, RH HOFFMEISTER \& M TRASHER. 2005. Knowledge of rare vocabulary in ASL and its relationship to vocabulary knowledge in English in Deaf children. Paper presented at the IASCL Conference, Berlin.

FOLVEN, RJ \& J BONVILLIAN. 1991. The transition from non-referential to referential language in children acquiring American Sign Language. Developmental Psychology, 65:806-816. 
FREIRE, S. 2009. Creating inclusive learning environments: Difficulties and opportunities within the new political ethos. Journal of Deaf Studies and Deaf Education, 14(1):131135.

FUNG, P, BW CHOW \& C MCBRIDE-CHANG. 2005. The impact of a dialogic reading programme on deaf and hard-of-hearing kindergarten and early primary school-aged students in Hong Kong. Journal of Deaf Studies and Deaf Education, 10(1):82-95.

GALVIN, D. 1999. Differences in the use of American Sign Language morphology by deaf children: Implication of parents and teachers. American Annals of the Deaf, 144(4):320324.

GOLDIN-MEADOW, S \& RI MAYBERRY. 2001. How do profoundly deaf children learn to read? Learning Disabilities \& Practice, 16(4):222-229.

GOLDSTEIN, G \& JM BEBKO. 2003. The profile of multiple language proficiencies: A measure for evaluating language samples of deaf children. Journal of Deaf Studies and Deaf Education, 8(4):452-463.

GORDON, N. 2004. The neurology of sign language. Review. Brain \& development, 26:146150.

HART, B \& T RISLEY. 1995. Meaningful differences in the everyday experience of young American children. Baltimore: Paul H. Brookes Publishing Co.

HELMUTH, L. 2001. From the mouths (and hands) of babes. Science, 1758-1759.

HOFFMEISTER, R, P DE VILLIERS, E ENGEN \& D TOPOL. 1998. English reading achievement and ASL skills in deaf students. Paper presented at the 21'st annual Boston University conference on language development. Brookline, MA: Cascadilla Press.

HOSKYN, M. 2004. Language Processes and Reading disabilities. In Wong, BYL (Ed), Learning about learning disabilities. San Diego: Elsevier Academic Press. 93-119.

KILIAN, D. 2001. English literacy as a second language in deaf grade one children: A Bilingual-bicultural perspective on the pedagogy of initial reading. Unpublished Master's dissertation, University of the Witwatersrand.

KIRSHNER, R. 2000. Communication disorders. In Hallahan, DP \& JM Kauffman (Eds), Exceptional Learners. Needham Heights, MA.: Allyn \& Bacon Co. 296-339.

LOTRTIET, A. 2002. Can short interpreter training be effective? In Hung, E (Ed), Teaching translation and interpreting 4: Building bridges. Amsterdam: John Benjamins. 83-98.

MARSCHARK, M. 2007. Raising and educating a deaf child: A comprehensive guide to choices, controversies and decisions faced by parents and educators. New York: Oxford University Press.

MAYBERRY, RI. 1994. The importance of childhood to language acquisition: Evidence from American Sign Language. In Goodman, JC \& HC Nusbaum (Eds), The development of speech perception. Cambridge, MA: MIT Press. 57-90.

MAYBERRY, RI. 2002. Cognitive development in deaf children: The interface of language and perception in neuropsychology. In Segalowitz, SJ \& I Rapin (Eds), Handbook of Neuropsychology. Amsterdam: Elsevier. 71-107.

MAYBERRY, R \& S FISHER. 1989. Looking through phonological shape to lexical meaning: The bottleneck of non-native sign language processing. Memory and Cognition, 17:740-754. 
MAYBERRY, RI, E LOCK \& H KHASMI. 2002. Linguistic ability and early language exposure. Nature, 417:38.

MEIER, RP \& EL NEWPORT. 1990. Out of the hands of babes: On a possible sign advantage in language acquisition. Language, 66:1-23.

MOELLER, MP. 2000. Early intervention and language development in children who are deaf and hard of hearing. Paediatrics, 106(3):1-9.

MORFORD, JP \& RI MAYBERRY. 2000. A re-examination of 'early exposure' to and its implications for language acquisition by eye. In Chamberlain, $\mathrm{C}, \mathrm{J}$ Morford \& $\mathrm{R}$ Mayberry (Eds), Language acquisition by eye. New York: Lawrence Erlbaum Associates Inc. 111-127.

MUSSELMAN, C. 2000. How do children who can't hear learn to read an Alphabetic Script? A review of the literature on reading and deafness. Journal of Deaf Studies and Deaf Education, 5(1):9-31.

NEVILLE, HJ \& JT BRUER. 2001. Language Processing - how experience affects brain organization. In Bailey, DB, J Symons \& JW Lichtman (Eds), Critical thinking about critical periods. Baltimore, Maryland: Paul Brookes Publishing Company. 151-172.

NEWPORT, E. 1990. Maturational constraints on language learning. Cognitive Science, 14:11-28.

NICHOLAS, GN \& AE GEERS. 2003. Hearing status, language modality and young children's communicative and linguistic behaviour. Journal of Deaf Studies and Deaf Education, 8(4):422-437.

NIEDERBERGER, N \& P PRINZ. 2005. La connaissanced'une langue des signes petu-elle faciliter l'apprentissage de l'écrit chez l'enfant sourd? (Does the knowledge of a natural sign language facilitate deaf children's learning to read and write?). Enfrance, 4:285297.

PADDEN, C \& C RAMSEY. 1998. Reading ability in signing deaf children. Topics in Language Disorders, 18(4):30-46.

PENFIELD, W \& L ROBERTS. 1959. Speech and Brain Mechanisms. Princeton: Princeton University Press.

PENN, C \& T REAGAN. 1990. How do you sign 'apartheid'? The politics of South African Sign Language. Language Problems and Language Planning, 14(2):91-103.

PENN, C \& T REAGAN. 1995. On the other hand: Implications of the study of South African Sign Language for the education of the deaf in South Africa. South African Journal of Education, 15(2):92-96.

PETITTO, LA. 1994. Are sign languages real languages? Evidence from American Sign Language and des Signes Quebecoise. Signpost, 7:1-10.

PETITTO, L \& P MARENTETTE. 1991. Babbling in the manual code: Evidence from the ontogeny of language. Science, 251:1493-1496.

POLAT, F. 2003. Factors affecting psychosocial adjustment of deaf students. Journal of Deaf Studies and Deaf Education, 8(3): 325-339.

POWER, D. 1998. Deaf and hard-of-hearing students. In Ashman, A \& J Elkins (Eds), Educating Children with Special Needs. Sydney: Prentice Hall Pty Ltd. 345-381. 
POWERS, S. 2002. From concepts to practice in Deaf Education: A United Kingdom Perspective on Inclusion. Journal of Deaf Studies and Deaf Education, 7(3):230-243.

PRINZ, P \& M STRONG. 1998. ASL proficiency and English Literacy within a bilingual deaf education model of instruction. Topics in Language Disorders, 18(4):47-60.

REAGAN, T. 1985. The deaf as a linguistic minority: Educational implications. Harvard Educational Review, 55:265-277.

REAGAN, T, C PENN \& D OGILVY. 2006. From Policy to practice: Sign language developments in post-apartheid South Africa. Language Policy, 5(2):187-208.

ROSS, E, C STORBECK \& K WEMMER. 2004. Psychosocial issues in pre-lingual deafness. In Ross, E \& A Deverell (Eds), Psychosocial approaches to health, illness and disability. Pretoria: Van Schaik Publishers. 141-176.

STORBECK, C. 2005. Educating the deaf and hard-of-hearing learner. In Landsberg, E, D Kruger \& $\mathrm{N}$ Nel (Eds), Addressing barriers to learning. Pretoria: Van Schaik Publishers. 348-362

STORBECK, C. 2005. Human rights in practice in South Africa: The irony of the Deaf education perspective. Paper presented at the International Special Education Conference on Inclusion, Glasgow, Scotland.

STORBECK, C \& J CALVERT-EVERS. 2008. Towards Integrated Practices in Early Detection of and Intervention for Deaf and Hard of hearing Children. American Annals of the Deaf, 153(3), 314-321.

STRONG, M \& P PRINZ. 1997. A study of the relationship between American Sign Language and English literacy. Journal of Deaf Studies and Deaf Education, 2(1):3746.

STRONG, M \& P PRINZ. 2000. Is American Sign Language skill related to English literacy? In Chamberlain, $\mathrm{C} \& \mathrm{~J}$ Morford \& R Mayberry (Eds), Language acquisition by eye. Hillsdale, NJ: Lawrence Erlbaum Associates. 131-141.

UNESCO. 1999. Consultation Report on Inclusive Education and the Deaf Child in South Africa. UNESCO Pretoria Office.

VALLI, C \& C LUCAS. 2000. Linguistics of American Sign Language: An introduction. Washington, D.C.: Gallaudet University Press.

VAN DER MERWE, E \& E ALANT. 2000. Die geskrewe taal van dowe leerders met dowe ouers en dowe leerders met horende ouers. South African Journal of Education, 20(1):74-84.

VAN STADEN, A, MG BADENHORST \& KGF ESTERHUYSE. 2008. Die ontwikkeling en evaluering van 'n visuele geletterdheidsprogram vir dowe grondslagfase-leerders met lees- en spellingagterstande. Journal for language teaching, 42(1):49-63.

YOSHINAGA-ITANO, C. 2003. From screening to early identification and intervention: Discovering predictors to successful outcomes for children with significant hearing loss. Journal of Deaf Studies and Deaf Education, 8(1):11-30.

YOSHINAGA-ITANO, C. 2004. Levels of evidence: universal newborn hearing screening (UHNS) and early hearing detection and intervention systems (EHDI). Journal of Communication Disorders, 37(5):451-465. 


\section{BIOGRAPHIC NOTE}

Annalene van Staden is a lecturer in the Department of Psychology of Education at the Free State University. Her research interests lie within the field of Educational Psychology, especially focusing on the emotional and scholastic support of learners with special educational needs (support teaching). Other research projects she is currently involved in are the development of literacy intervention programmes for deaf learners, learners with dyslexia and learners with mental disabilities.

Email: vanstadena.hum@ufs.ac.za

Elaine Ridge, a former lecturer at the Department of Curriculum Studies at the University of Stellenbosch, was also the previous editor of Per Linguam (until the end of 2008). Her valuable contribution to this article is hereby acknowledged by the other two co-authors.

Email: ridge@adept.co.za

Gerhard Badenhorst is a senior lecturer in the Department of Psychology of Education at the Free State University since 1994. He is a registered Educational Psychologist and his field of interests, are behaviour disorders, relationship disturbances and social issues. He was the promoter of dr van Staden for her PhD studies that focused on deaf learners, with specific reference to their literacy challenges and the effect of psycho-social factors on their experience world.

Email: badenmn.hum@ufs.ac.za 